\title{
Promoting School Based Cohorts in Distance/Online Learning
}

\author{
Janis McKinley, D. J. Champagne \\ Park University School for Education, Parkville, Missouri \\ Email: Janis.mckinley@park.edu, Debora.champagne@park.edu
}

Received June $18^{\text {th }}$, 2013; revised July $18^{\text {th }}$, 2013; accepted July $25^{\text {th }}$, 2013

\begin{abstract}
Copyright (C 2013 Janis McKinley, D. J. Champagne. This is an open access article distributed under the Creative Commons Attribution License, which permits unrestricted use, distribution, and reproduction in any medium, provided the original work is properly cited.
\end{abstract}

\begin{abstract}
Successful cohort online learning requires three important components: Community, Collaboration, and Content. Looking at how to develop these components is discussed as a result of what is known by the authors' active engaging in the cohort online learning model.
\end{abstract}

Keywords: Cohort; Online Learning Model; 3 C’s; Community; Collaboration; Content

\section{Introduction}

Online courses can be "just online courses". What makes a good, special, purposeful class? Our role with the "new classroom" is to help the student make sense of complexity by condensing the new style for learning into two or three critical goals. One such goal is that of forming a supportive learning community within the distance/online learning, what we refer to as a cohort. It is our intention to share a focus on three components necessary for student success specifically aligned with Park University's distance learning philosophy. These components are Community, Collaboration, and Content (McKinley \& Champagne, 2013). This discussion will elaborate on these three components and share both definitions of explanations for what we have found to be necessary in a successful Cohort model for learning.

\section{Cohort}

A cohort can be defined as a group of students treated as a single degree, program-seeking group. Cohorts typically share a professional identity and frequently teach within the same District (for the purposes of Educational Leadership and Teacher Leadership graduate degree programs). Cohorts are specifically recruited as a learning community throughout their program of study, working together to accomplish the same goal-degree completion. This definition embodies the early beliefs developed by Barnett and Muse (1993), describing the cohort as a group of students who begin and complete a program of studies together, engaging in a common set of courses, activities and/or learning experiences (p. 401). While we are developing cohorts for professional educators, it is clear that the cohort system is applicable to any like-minded degree candidates.

Research on cohort-based online learning has found the intentionally unified group of learners provides emotional and academic support to and for each member. This quality of support is directly linked to both motivation from and encouragement to persevere from the members. Findings show online discussion has the potential to increase critical thinking skills, leading to activity success. This quality is found to increase member satisfaction and reduce attrition (Lamb, Johnson, \& Smith, 1999-2010). Fisher and Baird's (2005) study found online learning, when connectedness and a sense of community among peers and instructor are established, positively influenced retention. A study conducted by Dietz-Uhler, Fisher and Han (2007) also showed retention rates lower in long distance online classes when compared with face-to-face classes. Barnard, Paton, and Lan (2008) found peer approval, in the online community, was valued and students wanted to be accepted by the members.

\section{The 3 C's}

\section{Community}

A benefit for cohort learning lies in establishing a sense of community. Community is a necessary element for cohort success. Community has a necessary quality of cohesiveness recognized and acknowledged by all cohort members. We believe a secure start when engaging in the first online-class is vital to developing this sense of cohesiveness. The idea "we are in this together" must be developed in the introduction to the class online platform. At Park University, personal introductions are a part of each Course Home. A guideline (rubric) for personal introduction is provided to encourage a presentation of each unique member involved in the learning community. Although a recruiting attempt is made for professionals already acquainted to one another to form a cohort, frequently cohorts develop online to which no one person may ever meet Face 2 Face (F2F). These introductions and sometimes pictures provide a commonality of purpose to group cohesiveness.

The Course Home contains information for what we believe to be necessary elements for success. We have discussed the introduction activity and the importance these statements play in cohesive relationship building. The syllabus and an explanation of how to navigate through the pieces/sections of the online 
course are necessary pieces for a secure start. Netiquette is a clearly established outline of communication etiquette expected as a part of the policy for all online communication. The course developer provides clear explanations of procedures and expectations with a course outline and rubrics for assessment of activities including communication in the weekly discussion threads-reinforcing netiquette. Positive support from the instructor helps to determine positive support between members, establishing a sense of togetherness and commitment.

Communication is an element critical to establishing community in cohort learning. The typed word must convey purposeful meaning to the other learners. No body language, no ability for instantaneous elaboration-unless writing in a Chat Room-makes online learning unique. The student must type what they mean AND mean what they say. Decoding by the reader can lend itself to interesting dialog strands within a discussion thread. Diligence, dedication, and the ability to edit and elaborate the words/language are keys to successful communication and thus the ability to maintain cohort cohesiveness (Jones, 2010). It is important the instructor use precise guidelines for participation or student's will not be as involved as they should be. It remains an important role of the instructor to reinforce and revisit those expectations through discussion threads.

\section{Collaboration}

Establishing the process for collaboration for online learning is the quality necessary for cohort success. When we promote cohort development with Districts or other degree-similar online learners we stress the importance of collaboration. Collaboration involves interactions with others, including peer to peer, student to faculty, and student to content. Collaboration needs structure in expectations and the use of rubrics. The instructor needs to use flexibility in order to listen to students and use good judgment in initiating elaboration of content items for clarity or changes in deadlines, as an example, to promote students success. Family emergencies, work duties, or computer problems can present unexpected interruptions in a student's ability to meet deadlines. Collaboration involves each member participating in the exchange of ideas and problem solving. Team development is suggested with each member being responsible for their on learning as well as the work of teammates (Lamb et al., 1999).

Communication that is collaborative and continual must be afforded to the cohort online model for learning. The rules for communication, having been initially established, will include consequences. Teaching and communicating in the classroom platform is a requisite. Avoiding private e-mails for questions and problems must be promoted by and for all class members. The instructor can determine the quality of cohesiveness in the learning community by how much support is visible in course talk; e.g. peer editing, APA format sharing, or calling a member out for lack of participation in the form of a "Welcome back $\mathrm{X} \cdots$ I have missed your critical dialog $\cdots$ discussion thread is not the same without you!"

There are several benefits to cohort development and the resulting collaboration during the learning process. Collaboration among members provides a platform for exchanging ideas and personal philosophies. The affects of supportive, quasi-mediated online interaction encourages continued participation through shared knowledge. Each participant is an expert in one or many best-practices. We have learned engagement, in the learning platform, must be clearly communicated to students along with a discussion rubric to ensure reflective response contributions. Collaboration in discussion thread activities has a schedule for original posting and required response to others. Collegiality cannot be assumed; rather it must be specifically encouraged by the quality instructor promoting engagement.

Sharing techniques and methods will encourage personal and professional skill growth. As an example, a student writes an original post, and through collaborative discussion develops a final outcome of an educational philosophy in a required activity. Kindergarten teacher, D. W. (2013) wrote as a final personal philosophy statement “... I do not follow any one particular education theory but combine ideas from many leaders in the field to develop a philosophy that best suits the needs of my particular group of learners ...” D. W. then provided specifics with descriptions/explanations of those best practices embedded in her personal philosophy of education. These postings in the weekly discussion threads of the online class provides an original post from which students receive feedback from peers encouraging continued critical thinking in the development of required activities for these "School Leader" candidates.

\section{Content}

Content of the online course is the third major component to be discussed. The content of each degree program provides for rigorous and relevant learning. The core learning objectives and outcomes are developed from professional standards appropriate to each degree program at Park University. In the graduate School for Education these standards are provided through the Missouri Standards for the Preparation of Educators (MoSPE), Interstate School Leader Licensure Consortium Standards (ISLLC), and the National Board for Professional Teaching Standards (NBPTS). Learning outcomes must be clearly identified and state what students must know and be able to do. These learning outcomes are established through professional licensing standards and are reflected explicitly in course learning outcomes. All online activities should be aligned with the course objectives and core learning outcomes. Assessment is necessary to show whether students learned the intended objectives.

Content is directly manipulated by the professor in the online classroom. In order for cohesiveness to be developed with cohort groups, the professor must communicate the purpose for study and the expectations guiding the study. As facilitator, the instructor should summarize important points and ideas, as well as provide a model linking theory to practice. They should encourage students to do the same by having critical discussions which challenge thinking and problem-solving. Specific and immediate feedback on individual and group assignments should be provided. In order to teach online courses, Park University requires successful completion of online-training for instructors through their own online learning in ED750 BOOT CAMP. Quality of instruction is a key to both accreditation and for cohort success. Instructors are given continued support at Park University with various links on the Park website. Support can be in the form of reviewing the course home, how to set up grading, designing introductions, lectures, assignments, exams, etc. There is also a forum for instructors to connect to each other to share strategies, thoughts, and other needs. 
A cohort is as successful as each individual member is successful. All activities are based upon key learning ingredients-communication, respect, and commitment. Students can be as actively engaged as much or more so in online learning classes, as opposed to F2F classes. More engagement in learning generally means more motivation and improvements in the thinking process (Barkley, 2010). Students can work in various group formats, as well as individually. Students can be in charge of asking questions to their peers on the discussion threads. Assignments and grades can be individual as well as group oriented. Pairing students can be used to review each other's papers. Each group member can have a specific role in the assignment, e.g., to summarize, research, encourage, and/or serve as recorder in order that each participant makes a substantive contribution.

Learning strategies including probing questions, the oneminute paper, the clearest/muddiest point of the lesson, jig-saw of an article, think-pair-share, and a daily journal can be used with online learning. Students can be divided into two groups and debate two sides of an issue. Case-studies of real-life situations can be easily discussed (McKinley \& Choi, 2013). Students participating in active, engaging classes report not feeling alone. They feel part of a community as they collaborate with others in rich, meaningful content (Online teacher evaluation, 2012).

Respect for each member must become a habit- "We are what we repeatedly do. Excellence, then, is not an act but a habit"... Aristotle.

Respect will become the rules of engagement for all communication in the class platform between peers/colleagues and student and instructor. Respect is a necessary but not sufficient element for commitment to the cohort online learning model. We believe that commitment follows respect.

Self-discipline for continued communication and engagement must be a trait possessed by each member. We believe this trait will be successfully reinforced with respectful engagement by all members of the cohort learning community. This communication and engagement by the instructor includes answering student concerns in a timely manner-Park policy requires at least 4 contact days per week, including weekends and in a timely manner within 24 and no more than 48 hours. Self-discovery-insight-by students must be facilitated as a best-practice by the instructor (DeFour, 2004).

\section{Conclusion}

In closing, the three areas of Community, Collaboration, and Content are necessary components for successful cohort online learning. The team concept must be embraced by cohort members. The university/college has a responsibility for developing standards-based core learning outcomes. The instructor guides learning by facilitating teaching and learning strategies. He/she is responsible for students' success. However, each student has an individual responsibility to their own learning and to the cohort "team" for outcomes-based achievement. This is what makes a purposeful cohort online learning model.

\section{REFERENCES}

Anonymous. (2013). Teacher evaluation comments. ED608 Assessment.

Barkley, E. (2010). Student engagement techniques. San Francisco, CA: Jossey-Bass.

Barnard, L., Patron, V., \& Lan, W. (2008). Online self-regulatory learning behaviors as a mediator in the relationship between online perceptions with achievement. International Review of Research in Open \& Distance Learning, 9, 1-11.

Barnett, B., \& Muse, I. (1993). Cohort groups in educational administration: Promises and challenges. Journal of School Leadership, 3 , 400-415.

D. W. (2013). Posted educational philosophy, kindergarten teacher comments. ED608 Assessment.

Dietz-Uhler, B., Fisher, A., \& Han, A. (2007). Designing online courses to promote student retention. Journal of Educational Technology Systems, 36, 105-112. doi:10.2190/ET.36.1.g

DuFour, R. (2004). What is a professional learning community? Educational Leadership, 61, 6-11.

Fisher, M., \& Baird, D. E. (2005). Online learning design that fosters student support, self-regulation and retention. Campus-Wide Information Systems, 22, 88-107. doi:10.1108/10650740510587100

Jones, V. R. (2010). Essentials for engaged $21^{\text {st }}$ century learners. Techniques. In V. A. Marcinkowski, \& L. Rehring (Eds.), The secondary school report: A final report on the development, pilot testing, validation, and field testing of the secondary school environmental literacy assessment instrument. Cincinnati, Ohio: Office of Research and Development, US EPA.

Lamb, A., Johnson, L., \& Smith, W. (1999). Teaching and learning at a distance.

http://eduscapes.com/distance/community_collaboration/cohort_grou ps.htm

McKinley, J., \& Champagne, D. J. (2013). "Promoting School-Based Cohorts in Distance Online Learning” at Missouri Association of Colleges for Teacher Education (MACTE) Spring Conference. Columbia: MO.

McKinley, J., \& Choi, D. H. (2013). KC Professional Development Council; Enhanced Teaching and Learning Conference. Kansas City: MO. 